\title{
LEX SALICA
}

\section{ZUM AKADEMISCHEN GEBRAUCHE}

\author{
HERAUSGEGEBEN UND ERLÄUTERT
}

vON

\section{HEINRICH GEFFCKEN}

DR. IUR. ET PHLL., A. O. PROFESSOR DER RECHTE AN DER UNIVERSITAT ROSTOCK.

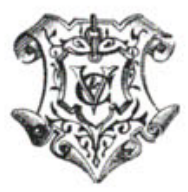

LEIPZIG

VERLAG VON VEIT \& COMP. 1898 
Drack on Metzger \& Wittig in Leipzig. 


\section{DEM ANDENKEN}

MEINES

HOCHVEREHRTEN LEHRERS UND VÄTERLICHEN FREUNDES

\section{DR. WILHELM ARNDT}

WEIL. 0 . $\ddot{0}$. PROFESSOR AN DER UNIVERSITÄT LEIPZIQ 
